The acknowledgement of the importance of the team of HPs runs in parallel with developments in the organization and activities of HPs within EULAR over the past years.

In connection with EULAR, there is a growing network of HPs from multiple professions across Europe. By working together, and collaborating with patients and rheumatologists and other physicians, EULAR HPs have achieved multiple milestones with respect to the quality of clinical care, education, and research over the past years and are equipped to encounter future challenges.

Disclosure of Interest: None declared

DOI: 10.1136/annrheumdis-2017-eular.7181

\section{SP0006 LOOKING BACK AT 70 YEARS OF EULAR AND 30 YEARS OF HP INVOLVEMENT: A NURSING PERSPECTIVE}

\section{J. Hill $^{1,1}$. Retired, -Harrogate, United Kingdom}

At the 1987 EULAR Congress held in Athens, a British nurse, Vicky Stephenson, arranged a meeting that was attended by about 30 health professionals. The meeting decided that a working group of Health Professionals from different professions and countries should work towards establishing a Standing Committee within EULAR. This was achieved in 1989 and since that time, the role of Health Professionals within EULAR has changed dramatically.

In this lecture, I will describe the evolution of rheumatology nursing over the past thirty years, and the part that EULAR has played in the dissemination, education and facilitation of best nursing practice and experiences within Europe. This will be illustrated by two pieces of work. In late 2009, EULAR part funded a Web-based survey to evaluate the status of extended roles undertaken by health professionals in Europe. The data from this survey relating to nursing has been extracted and analysed separately and will be presented. The following year, EULAR also funded a study to investigate the role of the nurse in the management of chronic inflammatory arthritis. The important recommendations resulting from this piece of work will also be shown.

Following the recommendations project, a number of other important nursing initiatives have been launched under the auspices of EULAR. These will be highlighted to enable delegates to understand how far rheumatology nursing has developed and how far it still has to go.

Disclosure of Interest: None declared

DOI: 10.1136/annrheumdis-2017-eular.7130

\section{SP0007 70 YEARS PAST AND A VIEW OF THE FUTURE: LOOKING BACK AND LOOKING FORWARD}

H.W. Bijlsma. Department of Rheumatology \& Clinical Immunology, University Medical Center, Utrecht, Netherlands

In 1913 the Dutch general practitioner Jan van Breemen, moved by the needs of the many disabled people in his practice, started an international cooperation to fight rheumatic and musculoskeletal diseases. His initiative led to the formation of the International League Against Rheumatism (ILAR), and subsequently to the formation of regional Leagues, such as EULAR in 1947.

EULAR has in the following 70 years developed into a unique organisation of rheumatologists, scientists, health professionals and patients, who together are aiming to reduce the burden of rheumatic diseases on the individual and society and to improve the treatment, prevention and rehabilitation of musculoskeletal diseases. To this end, EULAR fosters excellence in education and research in the field of rheumatology. It promotes translation of research advances into daily care and fights for the recognition of the needs of people with RMDs by the governing bodies in Europe (EULAR mission statement 2005).

The first European Rheumatology Congress was held in September 1947 in Copenhagen and was attended by 200 delegates from 16 countries. At the EULAR 2017 Madrid Congress over 14.000 attendees are expected, coming from more than 120 countries.

EULAR is unique in the sense that three pillars work closely together in one organization: rheumatologists, health professionals and patients. Today, I want to focus a bit on the health professionals pillar, since this pillar has its formal 30 years jubilee in 2017 as well. At the American celebration of 50 years of non-physician health professionals in Rheumatology (2015), Brady described three sciencedriven practice paradigm shifts that play an important role in managing patients with RMDs: 1 .The widely used "Self-management programs", that were developed from information giving and 'patient education'. 2. The positive and intensive use of "Exercise and physical activity", that were developed from previous acclaimed bed rest and assisted range of motion exercises. 3. The OMERACT initiated definitions and applications of Patient-reported outcome measures, instead of only biomedical assessment of disease activity.

In addition, she recognized two "evolutions in practice": 1.Understanding Psychological Factors, from accepting "the arthritic personality" to actively addressing depression, anxiety, coping skills, sense of control and confidence. 2. The development of the important role that nurses and other health professionals can play in the treatment of patients with RMDs.

The EULAR health professionals can be very proud of the important part that Europeans have played in these worldwide developments.

My priorities as president-elect of EULAR for the coming two years are:

- Further development of the School of Rheumatology
- Large public awareness campaign: Don't delay, Connect today

- New EULAR Strategy 2018-2023

I hope and expect that the pillar of health professionals will take an active role in the cooperation that is necessary to reach our common goals.

Disclosure of Interest: None declared

DOI: 10.1136/annrheumdis-2017-eular.7105

\section{SP0008 THE FUTURE FOR HEALTH PROFESSIONALS IN RHEUMATOLOGY}

A. De Thurah ${ }^{1,2} .{ }^{1}$ Department of Clinical Medicine, Aarhus University

${ }^{2}$ Department of Rheumatology, Aarhus University Hospital, Aarhus, Denmark

In recent years the prevalence of rheumatic diseases has raised leading to increased outpatient activity; at the same time, a general lack of rheumatologists has been described (1). This has created new demands from patients and the health care system towards innovative models of care, e.g. nurse-led follow-up (2), direct access strategies (3) and tele-health interventions (1). In the future this will call for extended and specialized roles for health-professionals within rheumatology, and for future development of compatibility of training of health professionals within the European countries.

Further, the current health-service development is confronting the population with increasing demands to understand and utilize health information and to navigate through this increasingly complex healthcare system. It requires that patients are capable of understanding and managing their health, and calls upon a strong focus on health-literate (HL) skills, and the formation of so-called HL organizations (4). In the future, health professionals within rheumatology will have a key role in supporting the development of $\mathrm{HL}$ responsive organizations through self-management strategies and patient centered care.

The present presentation will address some of these future demands for health professionals in Rheumatology

References:

[1] Ward IM, Schmidt TW, Lappan C, Battafarano DF. How critical is tele-medicine to the rheumatology workforce? Arthritis Care Res (Hoboken). 2016 Feb 11.

[2] Primdahl J, Sorensen J, Horn HC, et al. Shared care or nursing consultations as an alternative to rheumatologist follow-up for rheumatoid arthritis outpatients with low disease activity-patient outcomes from a 2-year, randomised controlled trial. Ann Rheum Dis. 2014 Feb;73(2):357-64.

[3] Hewlett S, Kirwan J, Pollock J, et al. Patient initiated outpatient follow up in rheumatoid arthritis: six year randomised controlled trial. BMJ. 2005 Jan 22;330(7484):171.

[4] Health Literacy; the solid facts. World health Organization, Regional Office [Internet]. 2013. Available from: http://www.euro.who.int/_data/assets/pdf_file/ 0008/190655/e96854.pdf.

Disclosure of Interest: None declared

DOI: 10.1136/annrheumdis-2017-eular.7155

\section{WEDNESDAY, 14 JUNE 2017 WIN \& HOT session}

\section{SP0009 WHAT IS NEW (WIN) IN PSORIATIC ARTHRITIS}

R. Lories. Skeletal Biology and Engineering Research Center, Dept. of Development \& Regeneration, KU Leuven, Leuven, Belgium

Novel therapies and targets have transformed the management of psoriatic arthritis and related skin disease psoriasis. The successful introduction and widespread use of anti-IL17, anti-IL12/23 and anti-PDE4 strategies have joined the ranks of TNF inhibitors. Novel biological insights into specific disease mechanisms are co-emerging with this new wave of treatment options. The different available treatments allow the community to further focus on optimal patient management aiming at remission or minimal disease activity. Yet, the assessment of the patient and his/her satisfaction with current health status remains challenging. Treat to target initiatives are trying to define optimal care and cure adapted to the specific characteristics of the disease. Molecular knowledge of the disease processes remains scattered and insufficient to build a comprehensive view on the disease for the individual patient that would allow the personalized definition of effective strategies.

Disclosure of Interest: R. Lories Grant/research support from: Celgene, Boehringer-Ingelheim, UCB, Consultant for: Janssen, Celgene, Novartis, Pfizer, UCB, Abbvie, Speakers bureau: Janssen, Celgene, Novartis, Pfizer, Merck, UCB, Abbvie

DOI: 10.1136/annrheumdis-2017-eular.7259 